\title{
Editorial
}

\section{The Burden of Nasal Congestion: Short- and Long-Term Efficacy of Medical Device-Based Approaches as an Adjuvant Therapy Targeting Symptoms}

\author{
Antonella Silvia Sciré ${ }^{1}$, Valerio Damiani ${ }^{2}$, Dario Gregori ${ }^{3, *}$ \\ ${ }^{\text {I} Z}$ Zeta Research Srl, Trieste, Italy \\ ${ }^{2}$ ENT Department San Giovanni Addolorata Hospital, Rome, Italy \\ ${ }^{3}$ Unit of Biostatistics, Epidemiology and Public Health, Department of Cardiac, Thoracic and Vascular Sciences, \\ University of Padova, Italy
}

Congestion, described as a feeling of fullness, blockage, or obstruction of the nasal cavities, is a symptom frequently encountered in clinical practice. In particular, it is one of the most common complaints dealt with in otorhinolaryngology, being a primary symptom in patients with rhinologic disease, such as allergic rhinitis, acute and chronic rhinosinusitis, and nasal polyposis $[1,2]$.

The principal cause of nasal congestion in common upper airway disorders is mucosal inflammation, which usually manifests as venous engorgement, increased nasal secretions, and tissue swelling that finally leads to the sensation of nasal blockage [3]. Congestion impacts negatively upon patient quality of life by interfering with both sleep and daytime activities In allergic rhinitis, for example, it is the symptom patients find most bothersome and would like most to prevent $[4,5]$. Taking into account the high prevalence of upper respiratory diseases, as well as the significant social and economic burden of nasal congestion [1], this symptom should be a key consideration in the treatment of patients with these disorders.

Though various pharmacotherapy options exist, including intranasal corticosteroids, topical and oral decongestants, H1 antihistamines and a variety of over the counter products for symptoms' relief, no agent is universally efficacious. In

*Address correspondence to this author at the Unit of Biostatistics, Epidemiology and Public Health, Department of Cardiac, Thoracic and Vascular Sciences, University of Padova, Italy; Tel: +39 049 8275384; Fax: +39 02 700445089; E-mail: dario.gregori@unipd.it addition, the upper airway respiratory diseases are generally undertreated due to the lack of efficacy with some current therapies and safety concerns with others [4]. Thus, there remains a large unmet clinical need for options for congestion, and further study and more effective therapies are necessary to improve treatment.

In this context, the role of medical devices is increasing as an alternative or a co-adjuvant therapy for the treatment of symptoms associated with rhinologic diseases, particularly due to their safety profile and the lack of the side effects generally related to the standard therapies. The studies presented in this thematic issue are providing an insight on the efficacy of an osmotically acting medical device, Narivent ${ }^{\circledR}$, both in a short- and a long-term treatment, in reducing nasal congestion and other symptoms in patients with various rhinopathies, thanks to its lubricant, antioedematous and anti-inflammatory actions.

\section{REFERENCES}

[1] Stewart M, Ferguson B, Fromer L. Epidemiology and burden of nasal congestion. J Gen Intern Med 2010; 8(3): 37-45.

[2] Fokkens W, Lund V, Mullol J, European Position Paper on Rhinosinusitis and Nasal Polyps group. European position paper on rhinosinusitis and nasal polyps. Rhinology 2007; 20 (Suppl): 1-136.

[3] Naclerio RM, Bachert C, Baraniuk JN: Pathophysiology of nasal congestion. Int J Gen Med 2010; 8(3): 47-57.

[4] Meltzer EO, Caballero F, Fromer LM, Krouse JH, and Scadding G: Treatment of congestion in upper respiratory diseases. Int $\mathrm{J}$ Gen Med 2010; 8(3): 69-91.

[5] Craig TJ, Sherkat A, Safaee S. Congestion and sleep impairment in allergic rhinitis. Curr Allergy Asthma Rep 2010; 10(2): 113-21.

(C) Sciré et al.; Licensee Bentham Open.

This is an open access article licensed under the terms of the Creative Commons Attribution Non-Commercial License (http://creativecommons.org/licenses/by$\mathrm{nc} / 3.0 /$ ) which permits unrestricted, non-commercial use, distribution and reproduction in any medium, provided the work is properly cited. 